\title{
NANOMATERIALS: PROS AND CONTRAS
}

In its first part the contribution presents basic characteristics of nanoparticles, their history, reason of their different behavior, classification of nanoparticles into natural, man-made and engineered nanoparticles. The article highlights potential risks of nanoparticles and the observation of the precautionary principle in contact with them. There is a special risk present in nanoparticles in the form of aerosols. Inhalation of aerosols consisting of nanoparticles leads to their deposition in the respiratory tract and due to their size they are expected to be further transported in the organism.

The contribution presents and discusses results of pilot experiments with the use of modern measuring devices, specifically determination of the quantity and distribution of nanoparticles in the air in an underground carriage during the regular operation, in a city transportation bus, in the working environment of an office building, during fires and their extinguishing, effects of the type of Diesel engine, lighting up of entertainment pyrotechnics and during welding. The last part of the contribution presents experiments demonstrating utilization of some properties of nanoparticles of C60 carbon - fullerene.

Key words: nanoparticles, classification of nanoparticles, toxicity of nanoparticles, working environment, precautionary principle, fullerene, radioprotective, nanocomposite

\section{Introduction}

Nanomaterials are solid particles with at least one dimension smaller than $100 \mathrm{~nm}$ [1]. Nanomaterials may be isometric (nanoparticles with all the three dimensions under $100 \mathrm{~nm}$ ), they may be in form of fibers (two dimensions smaller than $100 \mathrm{~nm}$ ) or layers (one dimensions smaller than $100 \mathrm{~nm}$ ).

The different behavior of nanomaterials can be explained in a simplified manner by the fact that physicochemical properties of solid substances are not the same inside the material and on its surface. When particles of a given material are smaller than $100 \mathrm{~nm}$ then physicochemical properties of the surface start to dominate over properties of the given material and the particles start behaving as if they consisted only of the surface. One of the most distinct demonstrations of this phenomenon is a significant increase of chemical reactivity, which may also result in a change of the toxicity.

Nanoparticles were used already in the past, despite the fact that their users were not familiar with their essential properties (in glassmaking, ceramics - glazes, chemical catalysis, metallurgy, production of soot, etc.) Nanoparticles have been surrounding us in real life since the time immemorial. They are generated during fires, volcano eruptions, erosions, chemical decomposition of organic matters by anthropogenic activity, i.e. e.g. by burning of fossil fuels (thermal power plants, combustion engines, etc.) and recently also engineered nanoparticles have been made in laboratories and in industrial plants. An overview of various sources of nanoparticles, both natural and man-made, is shown in a graphic form in Fig. 1.

Two principle processes may be used to produce nanoparticles. The process "TOP-DOWN" represents disintegration of big pieces of material while the process "BOTTOM-UP" means association of individual atoms and molecules into bigger nanostructures. There are three ways to do this: chemical (e.g. reduction), physical (e.g. pyrolysis with the use of laser) and mechanical (e.g. high-energy crushing).

Due to the fact that dimensions of nanoparticles are below the detection limit of optical methods, new technologies have been an important factor which has contributed to the development of nanotechnologies. Critically important was the invention of an electron microscope which enables to see and identify a three-dimensional structure of nanoparticles. The scientific discipline which deals with investigation of nanomaterials (nanoparticles), including development of materials and equipment of nano dimensions, is called nanotechnology. The current nanotechnology represents an interdisciplinary scientific discipline, which includes classical fields of science, such as physics, quantum mechanics, chemistry, biochemistry, electronics etc. Nanotechnologies are considered to be the phenomenon of the late $20^{\text {th }}$ and early $21^{\text {st }}$ centuries. In conformity

\footnotetext{
* Karel Klouda, Hana Kubatova, Eva Zemanova

State Office for Nuclear Safety, Czech Republic, E-mail: karel.klouda@sujb.cz
} 


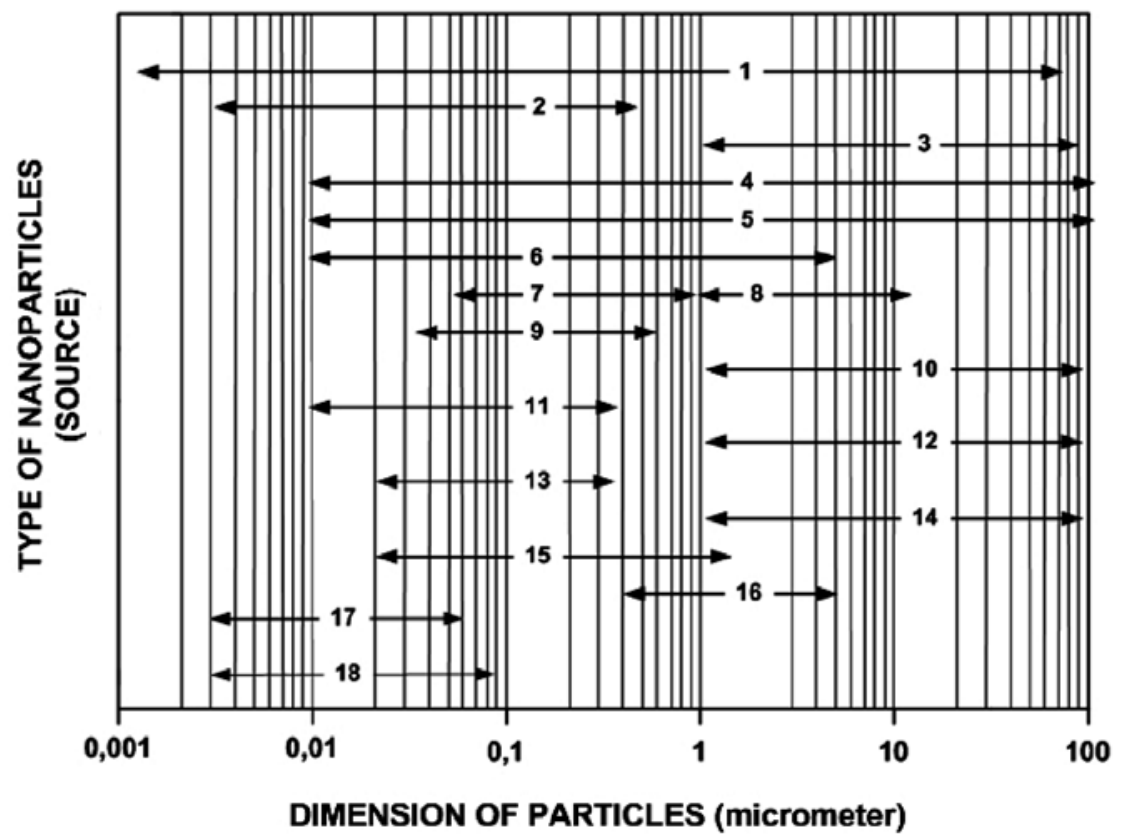

\begin{tabular}{|l|l|}
\hline 1 & Smoke from welding \\
\hline 2 & Exhaust fumes from Diesel engine \\
\hline 3 & Wind over a dusty landscape \\
\hline 4 & Flying ash \\
\hline 5 & Volcano emissions \\
\hline 6 & Paining pigments \\
\hline 7 & Smoke from crude oil fire \\
\hline 8 & Pollen \\
\hline 9 & Sea salt \\
\hline 10 & From drying (vacuuming) \\
\hline 11 & Coal soot \\
\hline 12 & Building activities \\
\hline 13 & Soot \\
\hline 14 & Mine dust \\
\hline 15 & Tabacco smoke \\
\hline 16 & Baceteria \\
\hline 17 & Virus \\
\hline 18 & Nucleation in the atmosphere \\
\hline
\end{tabular}

Fig. 1 Sources of nanoparticles and their dimension range

with this fact is the huge increase of support provided to the research in the concerned area. The development of nanotechnologies cannot be stopped.

\section{What are the potential risks posed by nanomaterials?}

After the negative experience with certain substances (e.g. DDT, $\mathrm{PCB}$, dioxins etc.) the worldwide public now requests the research centers and producers dealing with nanomaterials and nano-technologies to observe the so-called precautionary principle. Recommendations have been made for regulation, registration, determination of risk assessment methods and monitoring of nano-compounds [1] (COM 1 2000, COM 243 2005, COM 338 2004, COM 345 2008), policy framework for California to deal with nanosubstances [2], prohibition to use nano-compounds in foodstuffs without execution of risk assessment (European Parliament, March 2009) etc. In terms of the potential risks posed by nanomaterials the following classification may be used:

- dangerous for health (toxicity),

- dangerous for the environment (ecotoxicity),

- physicochemical risks, i.e. they may cause fire, explosion, uncontrolled and undesired reactions,

- in the future it is impossible to exclude an unethical use of nanotechnologies and nanoparticles by a third party (criminal or terrorist act, war conflict).

The first two potential sources of danger are mutually very closely interconnected as the occurrence of nanoparticles in the elements of the environment enables their contact with living organisms. The presence of nanoparticles in a living organism results in a number of interactions between their surfaces and biological systems. The interactions may lead to formation of protein coronas, wrapping of particles, intracellular absorption and biocatalytic processes, which may have positive and negative results in terms of the toxicity. The organic world intertwines with the synthetic world of man-made nanomaterials. The nano-bio interfaces are created, associated with dynamic physicochemical interactions, kinetic and thermodynamic exchanges between surfaces of nanomaterials and surfaces of biological components (proteins, membranes, lipids, DNA, biological liquids etc.). A background research [3] has shown that only very little is known about what happens with nanoparticles inside a cell. Nanoparticles may cause a wide range of intracellular reactions which depend on their physicochemical properties, intracellular concentration, duration of contact etc.

There is a general agreement among authors [3] dealing with toxicity of nanomaterials that the primary driving force behind the bioactivity of nanoparticles is the size of their surface. A surface coat on nanoparticles (e.g. hydrophobic polymer) increases the safety of nanoparticles and reduces their bioreactivity. The biggest problem is that the information we have gathered about one specific nanomaterial may not be applicable for the same particles if they are made synthetically or slightly modified. Another problem is the characterization of the surfaces with simple and available measuring equipment. It is also assumed that natural nanoparticles will behave differently from the so-called "engineered nanoparticles" i.e. nanoparticles made in industrial plants or in laboratories [4, 5].

Physicochemical risks are present particularly in the production of nanoparticles using the "TOP-DOWN" system, where nanoparticles are created by a mechanical method i.e. e.g. grinding, cutting, supermilling etc. It should be noted and stressed here, that nanopar- 
ticles are present essentially in all dusty operations which include e.g. metal machining, woodworking, milling, grinding, welding, etc. Their numbers and reactivity are influenced by the degree of their mutual aggregation or agglomeration. In general, it is typical for dust-air mixtures not to be stable in terms of place and time, they are not homogenous. The explosiveness of dust is strongly influenced by the size of particles. The general risk of explosion increases with the reducing size of the particles. This statement has been verified experimentally for microparticles and one can assume that the trend will continue to apply also to particles of nanometric size. Many nanoparticles e.g. $\mathrm{Fe}, \mathrm{Ni}, \mathrm{Al}, \mathrm{Mn}, \mathrm{Co}$ are prone to self-ignition and thanks to their large surface they operate as active catalysts and thus may initiate an uncontrolled exothermic reaction. Nanoparticles as such are more reactive than their "macro versions" with the same chemical composition. A special risk is posed by nanoparticles in form of aerosols, i.e. particles suspended in the air. Inhalation of aerosols consisting of nanoparticles leads to their deposition in the respiratory tract and they are expected, depending on their diameter, area and surface etc., to be further transported in the organism into other peripheral organs. There are a number of epidemiological studies which have identified the negative effect of nanoparticles on respiratory and cardiovascular systems in susceptible groups of population. It has been discovered that exceptionally serious is the cardiovascular effect of inhaled ultrafine (nano) particles [6]. Those particles come mostly from anthropogenic sources (road traffic, combustion products, forest fires, fires of organic matters and crude oil products etc.) and they occur in urban agglomerations.

This was one of the reasons to perform the measurements of nanoparticles in transportation means in Prague, in an office building in the city center and at different types of Diesel engine, to identify the quantity of nanoparticles released into the atmosphere and to check the level of risk caused by nanoparticles to fire fighters during an intervention against fire. We also measured production of nanoparticles during welding and lighting up of entertainment pyrotechnics. We also selected one chemically non-active nanoparticle of carbon - fullerene - which occurs in soot from burning wood, soot from fire of organic and crude oil products, in emissions from coal power plants, car exhaust fumes, in municipal emissions etc. [7-13]. With those nanoparticles we focused on their potential "favorable" use as a radioprotective, radical-based extinguishing agent and nanocomposite.

\section{Pilot measurement of quantities and distribution of nanoparticles from various anthropogenic sources}

\section{Measuring points:}

I. Prague underground carriage, under operating conditions, line $\mathrm{C}$,

II. City transportation bus (MHD) in Prague No. 189, under operating conditions

III. Car driving on the same route as the bus No. 189,

IV. Office building in the center of Prague, Senovážné nám. Dlážděná street,

V. At fires with various composition of burning materials,
VI. At exhaust pipes of a regular Diesel engine and of a modern environment-friendly engine,

VII. Simulation of lighting up of entertainment pyrotechnics,

VIII. Welding in a maintenance workshop.

The following conclusions may be drawn from the results:

- It is impossible to positively define a small increase in the quantity of nanoparticles depending of the occupation rate in the underground carriage. Other involved factors may include the ground-level location of the stations and the routes which are close to the extremely busy arterial road (ventilation shafts).

- The concentration of nanoparticles which affects passengers in the city transportation bus No. 189 is by one order of magnitude higher than in the underground on the line $\mathrm{C}$ ( $\max .36 .7 .103$ $\mathrm{N} / \mathrm{cm}^{3}$ in the underground carriage, $260.103 \mathrm{~N} / \mathrm{cm}^{3}$ in the bus). Even in this case it is impossible to demonstrate a positive effect of the number of passengers on the concentration of nanoparticles but it is rather the effect of intensity and composition of the traffic.

- The effect of intensity of the surrounding traffic was demonstrated by measurements in a driving car: the quantity of particles increased in the proximity of a slip road to the Prague ring road and D1 motorway (location Kačerov).

- A certain protection of persons against nanoparticles in a driving car may be provided by lower ventilation intensity and pollen filter.

- Probably the most risky particles are those smaller than $50 \mathrm{~nm}$ due to their potential ability to penetrate cellular protective barriers. Particles of that size were primarily identified in the proximity of Kačerov, which is again the location close to a slip road to the Prague ring road and D1 motorway. In the underground it was the section (although with a much lower value than in the bus) that passes through the center of Prague near the arterial road (Pankrác - Florenc).

- Alarming was the finding that particles smaller than $40 \mathrm{~nm}$ were those measured most frequently in the city bus.

- The number of nanoparticles in the office building used by nonsmokers for regular office activities was slightly lower than in the proximity of the building (ca. units $.103 \mathrm{~N} / \mathrm{cm}^{3}$ ).

- When measuring nanoparticles on individual floors in the building wing in the Dlážděná street no relation was found between the quantity of nanoparticles and the floor level.

- An extreme increase of the number of nanoparticles was found in an office where people regularly smoked. When three people were smoking at the same time in the office the number of nanoparticles increased by up to two orders of magnitude (their values were comparable with those for traveling in the city traffic).

- An increased number of nanoparticles was also found in a regular maintenance workshop.

- During fires and during their extinguishing there is a high increase of aerosol nanoparticles, depending on the composition of burning components (the measuring devices got congested with products of combustion of mostly crude oil-based materials).

- An increase of the total amount of aerosol nanoparticles was found for the classical Diesel engines but in the case of a modern Diesel engine we found an increased number nanoparticles whose 
size makes them more risky for human health and for the environment (for comparison see Figs. 2 and 3).

- It was demonstrated that the concentration and size of nanoparticles changes depending on the distance from the source (see Fig. 3). This is caused by dispersion and mainly by coagulation of the particles (aggregation, agglomeration, adsorption of nanoparticles on microparticles, etc.).
- The risk area of that size of nanoparticles was also found in the case of the regular engine, before it was heated to the operating temperature (see Fig. 2).

- Apart from particles generated by the fire and its extinguishing, firefighters are also exposed to nanoparticles that may be produced by their own firefighting technology, i.e. by fire-fighting trucks, Diesel aggregates, etc. (see Fig. 4).

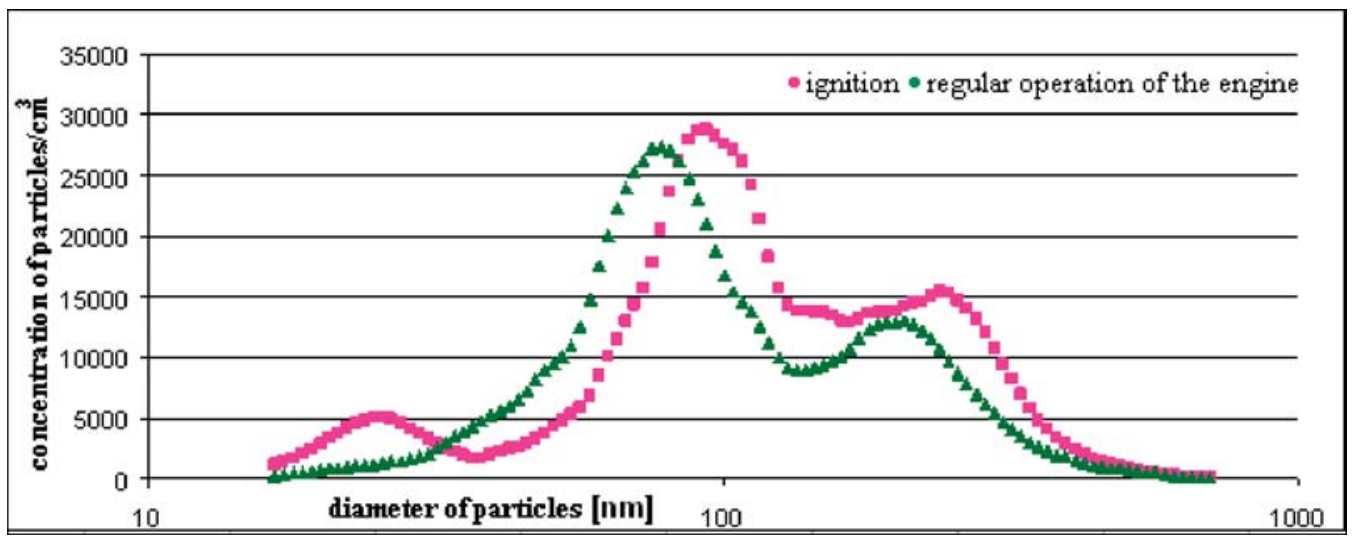

Fig. 2 Distribution of particles measured at a Diesel engine made by Zetor, exp. VI.a)

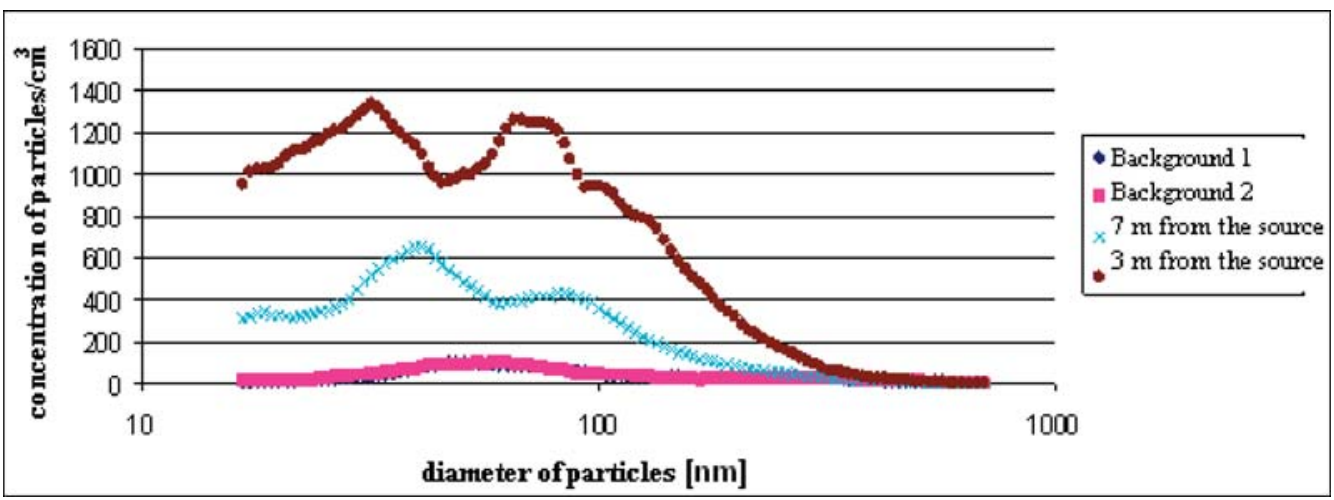

Fig. 3 Distribution of aerosol particles measured at the exhaust pipe of Ford Transit exp. VI.b)

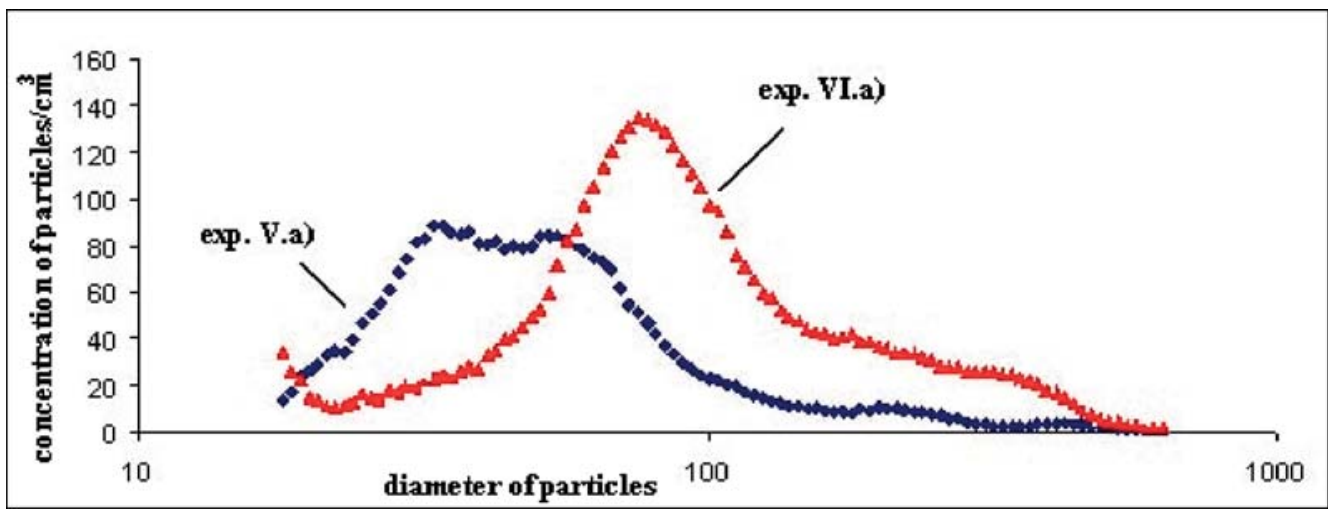

Fig. 4 Distribution of particles exp. V.a) - fire, exp. VI.a) - Diesel engine type Zetor 
- The increase in the number of nanoparticles after lighting up of entertainment pyrotechnics is two orders of magnitude in comparison with the background levels.

- The size of nanoparticles produced by the lighting up of entertainment pyrotechnics is greater than $100 \mathrm{~nm}$ - as measured in a relatively big distance from the source. Also in this case we could observe the time dependence of coagulation.

- Dangerous nanoparticles smaller than $100 \mathrm{~nm}$ are generated immediately in the course of welding and they subsequently coagulate.

The presented results of the performed experiments have the character of only basic measurements. It is very difficult to measure the number of nanoparticles and the results are influenced by many factors (e.g. air flow, temperature, humidity, distance from the source etc.). It is nearly impossible to get reproducible results of measurements and it is one of the biggest problems of standardization of nanoparticles in respect to their impact on human health (toxicity) and the environment. For this reason the published conclusions shall be applicable only for the specific situation [14].

Alarming was the finding that particles smaller than $50 \mathrm{~nm}$ were essentially most frequently present during fires, fire extinguishing, welding and at exhaust pipes of a modern Diesel engine and of a cold classical Diesel engine. This corresponds to the discussion and statement [15] that improved combustion in modern Diesel engines extremely reduces the ratio of big particles, however, at the expense of increased emissions of extremely small particles. As the authors say: "The fact that you see no smoke coming out from the exhaust pipe is reassuring for the eye but the problem is actually in something that cannot be seen." We dare say that the same applies for fires.

\section{Fullerene - carbon nanoparticles}

Carbon is the basic element which forms organic compounds and it has two allotropic forms - graphite and diamond. The third carbon modification was discovered in 1985 (R. E. Smalley and R. F. Curl - American professors and British professor H. W. Kroto, they received the Nobel prize for chemistry in 1996), which are giant molecules made of more than twenty atoms of carbon situated in the corners of various polyhedrons, including more or less spherical shapes. Those molecular formations were called fullerenes in remembrance of the renowned American architect R. B. Fuller (they are similar to a skeleton of the geodesic dome designed on the occasion of the World Exhibition in Montreal in 1967).

The best known and, by its properties, the most interesting molecule from among fullerenes is the molecule $\mathrm{C}_{60}$. In comparison with other fullerene molecules it has the most perfect spherical shape and the structure of truncated icosahedrons, whose surface is made up of twenty hexagons and twelve pentagons (analogy to a football), see Fig. 5 .

The basic difference from graphite and diamond is the solubility of $\mathrm{C}_{60}$ in non-polar organic solvents, such as THF, toluene, benzene,

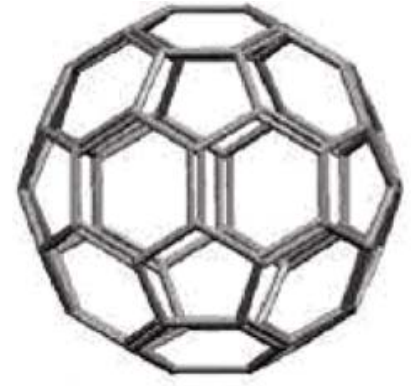

Fig. 5 Structural molecule $C_{60}$

1, 2 dichlorobenzene, xylene, carbon disulphide etc. Colors of such solutions are varied, e.g. brown-yellow, violet, red-violet and they are symptomatic for the transition of $\pi-\pi$ electrons.

Reactivity of fullerene is associated with the internal tension in the molecule, which is caused by non-planar arrangement of hybrid $s p^{2}$ orbitals of the carbon atom. Therefore it typically features reactions associated with transformation into $s p^{3}$ configuration which leads to a reduction of the internal tension in the molecule. Moreover, the $\mathrm{C} 60$ molecule is electropositive, which means preference of nucleophilic or radical addition to form multiple bonds.

The solubility of fullerene $\mathrm{C}_{60}$ in organic solvents is the first precondition for a number of syntheses [16]. Results of available studies that are based on the effects of fullerenes on living organisms are in many respects mutually contradictory [15]. The experiments that we have performed focused on utilization of the ability of the fullerene molecule to catch radicals and to use is as a radioprotective, radical extinguishing agent or nanocomposite in organic polymers.

\section{Radioprotective properties of $\mathbf{C}_{60}$ fullerene derivative}

Effects of ionizing radiation on organisms and post-irradiation changes at the molecular level are associated particularly with mechanisms related to the formation of reactive water metabolites. The probability of a direct hitting of an organic molecule (its excitation and ionization) is relatively small in comparison with a cascade of degradation radical reactions, which are caused by reactive metabolites generated by radiolysis of water. Hydrogen atoms and electrons are immediately caught by molecular oxygen to form superoxide. Extremely reactive is the hydroxyl radical, which immediately, at the place of its formation, reacts with all biomolecules (saccharides, aminoacids, phospholipids, nucleotides and organic acids) and strips them of hydrogen. This launches other radical reactions with the resulting damage of membranes. The radical reacts in the same manner with deoxyribose in DNA. It is also capable of an addition reaction with aromatic rings of purine and pyrimidine bases, which are a part of DNA and RNA. The reason of the limited development of $\mathrm{C}_{60}$ alone in biological applications is its minimum solubility in the water environment. But thanks to its reactivity it is possible to perform its organic functionalization with hydrophilic groups, which increases its solubility in water. 


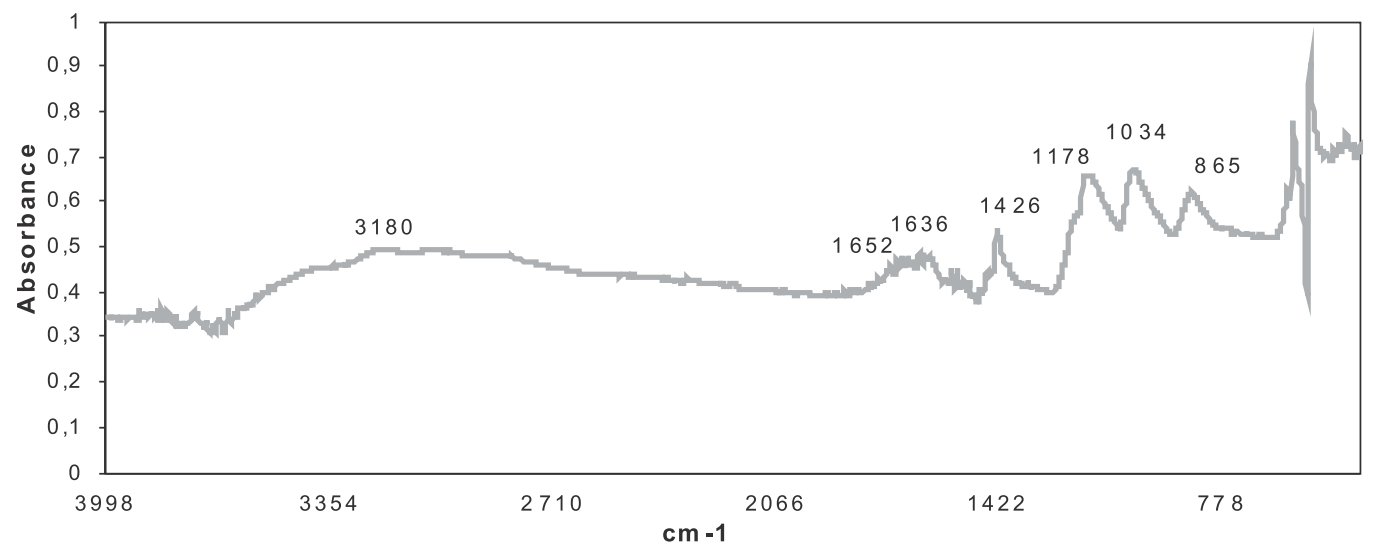

Fig. 6 FTIR spectrum of the prepared fullerene derivative

This inspired us to prepare a derivative of fullerene (DF) functionalized with $-\mathrm{OH}$, - $\mathrm{COOH}$ by means of its oxidation with peracetic acid /17/.This derivative is partly soluble in water and its FTIR spectrum is shown in Fig. 6

For the purposes of our experiments we prepared 65 liters of DF stock solution with the concentration of $147 \mathrm{mg} / 1$. Fig. 7 shows the difference between the initial fullerene and its derivative.

The selected model biological organism used for our experiments was the Danio rerio fish in juvenile age ( 2.5 months) without sex differentiation. This small vertebrate species has become a successful model system to study human diseases; it reproduces quickly and it is easy to keep in laboratory conditions. Before the test of radioprotectiveness as such we performed a toxicity test in vivo. After the toxicity test we concluded that 28 days of exposure of the Danio rerio fish to DF solution with the concentration $147 \mathrm{mg} / \mathrm{L}$ $\pm 0.1 \mathrm{mg} / \mathrm{L}$ had no effect on their behavior or alimentary patterns
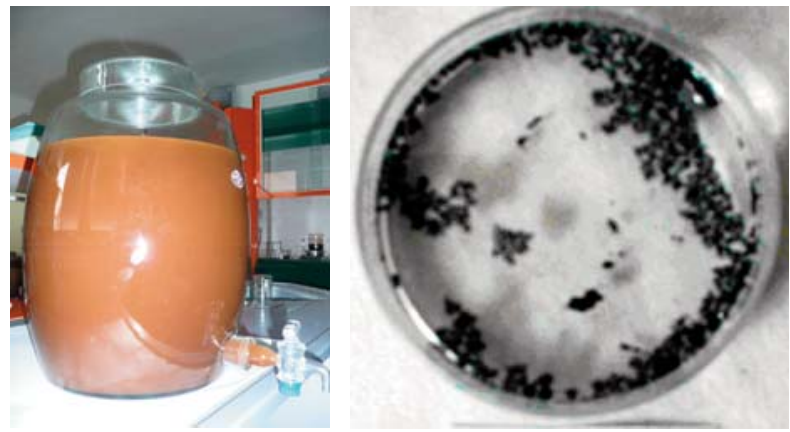

Fig 7 Supply tank with DF water solution in comparison with an insoluble $C_{60}$

in comparison with the control group. In a subsequent period of time the tested fish was kept in DF-free water and we did not find any visible changes in the behavior of the fish in comparison with the control group either. Therefore it is possible to conclude that

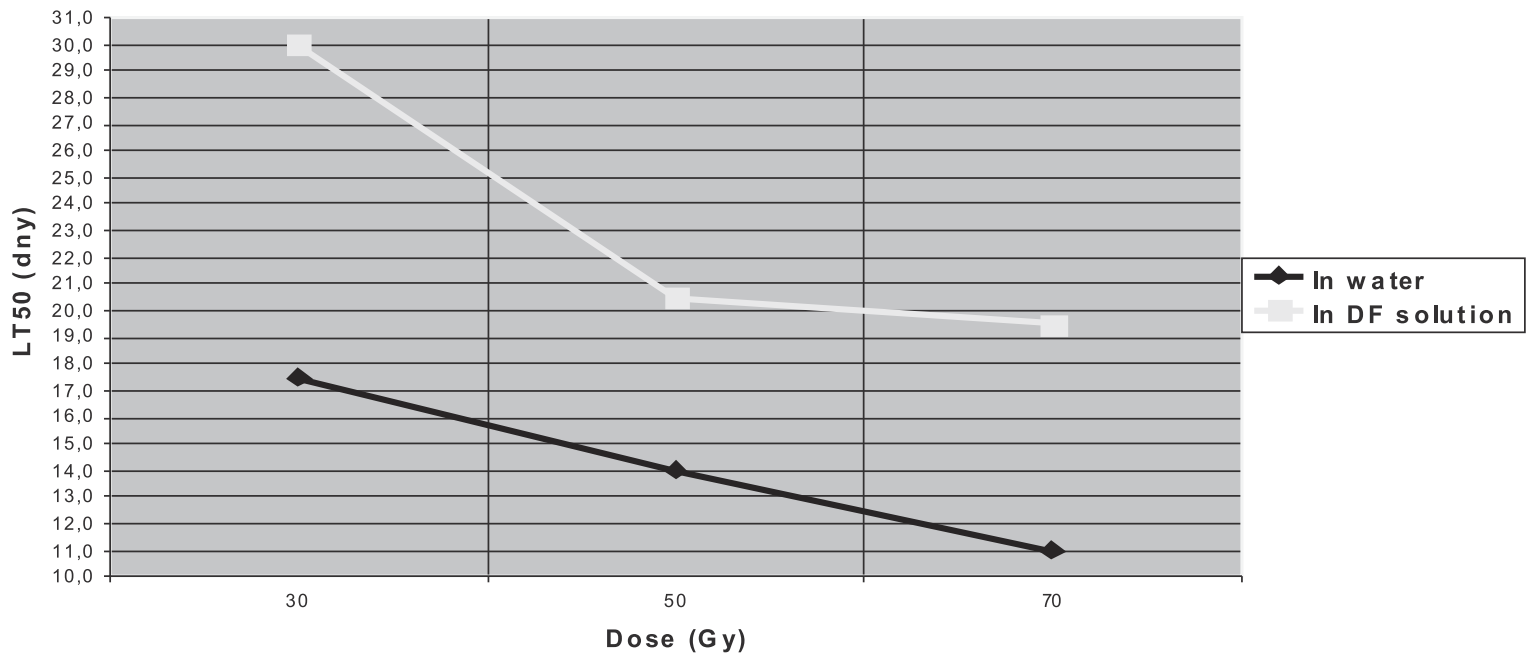

Fig. 8 Comparison of LT 50 after irradiation at Danio trio kept in water and DF solution 
the 28-day exposure of the fish to the DF solution with the concentration $147 \mathrm{mg} / \mathrm{L} \pm 0.1$ did not have any visible negative effect on their health condition.

The test of radioprotective properties of DF consisted of monitoring and comparison of the survival time of Danio rerio that was before the irradiation kept for 5 days in water containing $147 \mathrm{mg} / \mathrm{l}$ $\mathrm{DF}$, with the fish kept only in water.

The irradiation of the individual groups of the fish was with $\mathrm{X}$ radiation with the doses $10,30,50$ and $70 \mathrm{~Gy}$ (therapeutic linear accelerator Climac 2100CD). Details of the course of the experiments and their detailed results were presented at conferences Nanocon 2009 and 2010 /17, 18/ Radioprotective effect of DF i.e. increase of LT 50 as a result of DF is shown in the diagram in Fig. 8.

The exposure to $10 \mathrm{~Gy}$ resulted in the mortality of the fish in water up to $10 \%$, LT50 was not determined. For the fish in the DF solution the mortality after the exposure to $10 \mathrm{~Gy}$ was zero. The biggest effects of DF was found for the exposure to doses 30Gy and 70 Gy and LT50 increased by $71.4 \%$ and $77.5 \%$ respectively. For the exposure to $50 \mathrm{~Gy}$ LT 50 increased by $46.5 \%$. LT 50 indicators were nearly the same within the observation error ( $\max . \pm 1$ day) for the fish kept in DF an exposed to the doses 50 and $70 \mathrm{~Gy}$.

The completed detailed experiments have shown that the development of the mortality is not dependent on the duration of exposure to DF solution after the irradiation. Results of the tests are identical for organism kept in the DF solution for the entire monitored period, for the fish relocated into water after one week after the irradiation and for the fish placed into water immediately after the irradiation. Therefore we do not consider the effect of DF to be "curative".

\section{Use of fullerene and its derivative in fire protection}

The basic principle of fire fighting capacity of the aerosol system is the reaction of radicals formed from the fire-fighting composition and radicals from burning. The test involved extinguishing capacity of aerosols used by FIRE JACK BR-1 (composition: potassium nitrate, dicyandiamide, phthalic acid, formaldehyde resins) without fullerene $\mathrm{C}_{60}$ and with fullerene, whose content in the composition was $1-5 \%$. The experiments have shown that to extinguish the same quantity of n-heptane requires less than a half of the composition that contains fullerene [19].

Nanocomposites are new materials which have been currently intensely investigated and they promise extensive applications [20]. The materials consist of a polymeric matrix and a non-polymeric component - filling agent - while the filling agent has at least one of its dimensions in the nano range. It may consist of isometric nanoparticles, nanotubes or stratified nanoparticles. Nanocomposites have better mechanic and material properties than polymers alone and they have an increased thermal stability and significantly reduce heat release rate. In cooperation with the Technical University in Liberec we tested the possibility to introduce DF as a nanocomposite into nanofibers made of polyvinyalcohol. Results of DTA nanofibers prepared only from PVA and from PVA with DF have shown that the nanofiber containing DF demonstrated a lower quantity of released heat in case of an exothermic decomposition.

\section{References}

[1] KVASNICKOVA, A.: The Use of Nanotechnology in Food Processing Industry (in Czech), [on-line], [cit. dne 2009-06-21], In: http://www.agronavigator.cz/User Fi...

[2] A Nanotechnology Policy Framwork for Kalifornia, [on-line], [cit. dne 2009-06-8], dostupné z: http://www.nsti.org/proces/Nanotech $2009 \mathrm{v} 2 / 7 / \uparrow 82.708$

[3] NEL, A. E., MADLER, L., VELEGOL, D., XIA, T., HOEK, E. M. V., SOMASUNDARAN, P., KLAESSIG, F., CASTRANOVA, V., THOMPSON, M.: Understanding biophysicochemical interactions at the nano-bio interface, Nature Materiale, 2009, Vol. 8, No. 7, pp. 543-557

[4] KLOUDA, K., KUBATOVA, H., VECERKOVA, J.: Engineered Nanomaterials. Methodology Draft for Risk Management Process During Nanomaterials Production and Handling (in Czech), Proc. of Ochrana obyvatel 2010, Ostrava, pp. 138-151, ISBN 978-807385-080-7, ISSN 1803-7372

[5] KLOUDA, K., KUBATOVA, H., VECERKOVA, J.: Engineered Nanomaterials. Methodology Draft for Risk Management Process During Nanomaterials Production and Handling (in Czech), Spektrum 1/2010, pp. 41-45, ISSN 1211-6920

[6] NOHAVICA, D.: Respiratory and Cardiovascular Problems Related to Nanoparticles (in Czech), Proc. of NANOCON 2009, Roznov pod Radhostem, 2009, p. 76, ISBN 978-80-87294-12-3

[7] CUVANOVA, S., TURCANIOVA, L., KOVACIK, V., BEKESOVA, S., LOVAS, M., HREDZAK, S.: Acta Metallurgica Slovaca, 12, pp. 60-66, 2006

[8] REILly, P. T. A., GIERAY, R. A., WHITTEN, W. B., RAMSEY, J. M.: J. Am. Chem. Soc. 122, pp. 11596-11601, 2000

[9] NOVACK, B., BUCHELI, T. D.: Environmental Pollution 150, pp. 5-22, 2007

[10] DUNNE, J., NOZAN, P. F., MUNN, J., TERRONES, M., JONES, T., KATHIRGA MANATHAN, P., FERNANDEZ, J., HUDSIN, A. D.: Phys. Condens Mottem 9, 1 pp. 0661-10673, 1997 
[11] REILly, P. T. A., WAITTEN, W. B., RAMSEY, J. M.: J. Am. Chem. Soc. 122, pp. 11596-11601, 2000

[12] UTSUNOMIYA, S., JENSEN, K. A., KEELER, G. J., EWING, R. C.: Environmental Sien. Techn. 36, pp. 4943-4947, 2002

[13] MUUR, L. E., SOTO, K. F., GARZA, K. M., GUERRERO, P. S., MARTINE, Z. R., ESQUIVEL, V. E., RAMIREZ, Y., SHI, Y., BANG, J., VENZOR, J., Int. J. Environ. Res. Public Health 3, pp. 48-66, 2006

[14] KLOUDA, K., VECERKOVA, J., JILEK, K., FRONKA, A., BEDNAROVA, L.: Occurrence of Nanoparticles in Common Working (natural) Environment (in Czech), BOZP 2010, Ostrava, sborník pp. 108-124, ISBN 978-80-248-2207-5

[15] GLATZ, A.: Efficiency of Emission Particles Filters and Modern Engines Ecology are strongly Arguable (in Czech), [cit. 2010-03-16], dostupné z http://biom.cz/odborne-clanky/efektivita-filtru...

[16] KLOUDA, K.: Possible Risk of Carbon Nanoparticles Presence in the Solid Products of Combustion (in Czech), SPEKTRUM 2/2009, pp. 50-54, ISSN 1211-6920.

[17] BERANOVA, E., KLOUDA, K.: $C_{60}$ Fullerene Derivate Prepartaion of Water-Soluble Fullerene Derivate in Reaction with Peracetic Acid, Proc. of Nanocon 2009, pp. 139-148, Roznov pod Radhostem, 2009, ISBN 978-80-87294-12-3.

[18] BERANOVA, E., KLOUDA, K., VAVRA, L., ZEMAN, K., MACHOVA, L., ZENKA, J., DANIHELKA, P.: Radioprotective Properties and Toxicity Test of $C_{60}$ Fullerene Derivative in Vivo\&in vitro, NANOCON 2010, Olomouc, ISBN 978-80-87294-18-5.

[19] KLOUDA, K., CAFOUREK, S.: The role of Fullerene C60 in the Aerosol Method of Fire Suppression (in Czech), Proc. of Pozarni ochrana, 2009, Ostrava, sborník pp. 260-263, ISSN 1803-1803.

[20] MORGAN, A. B., WILKIE, CH. A.: Flame Retardant Polymer Nanocomposites, Wiley-Interscience, 2007, ISBN 978-0-471-73426-0. 